\title{
Competitividad turística en la ciudad de Cartagena como herramienta para el crecimiento del sector turístico ${ }^{1}$
}

\section{acceso $\mathbf{\sigma}$ abierto}

Para citaciones: Gonzalez, J., Morales, T. (2020). Competitividad Turística en la Ciudad de Cartagena Como Herramienta Para el Crecimiento del Sector Turístico. Revista de jóvenes investigadores Ad Valorem, 3(1), 65-67.

Editor: Bernardo Romero Torres. Universidad de Cartagena-Colombia.

Tipología IBN Publindex: Artículo de investigación científica y tecnológica
Copyright: (C) 2020. Gonzalez, J., Morales, T.. Este es un artículo de acceso abierto, distribuido bajo los términos de la licencia Creative Commons AtribuciónNoComercial-SinDerivados 4.0 la cual permite el uso sin restricciones, distribución y reproducción en cualquier medio, siempre y cuando que el original, el autor y la fuente sean acreditados.

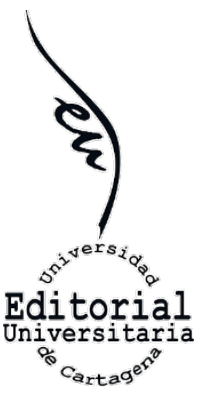

\author{
Jesús Alberto González Tamara², Teófilo Morales Maestre ${ }^{3}$ \\ Universidad de Cartagena - Colombia
}

\section{RESUMEN}

El presente documento explora la competitividad turística en la ciudad de Cartagena, con el objetivo de conocer el estado en que se encuentra los indicadores de competitividad para el crecimiento del sector turístico. La investigación tiene como soporte teórico El Modelo de Competitividad de Destinos Turísticos de Larga Distancia de Ritchie y Crouch, a su vez, para conocer el estado de los indicadores de competitividad se desarrolla el Índice de Competitividad Turística propuesto por el Foro Económico Mundial calculado para el año 2016 en la ciudad de Cartagena. El micro entorno competitivo y el macro entorno competitivo son, para Ritchie y Crouch los factores que influyen en el sistema, mientras que, los pilares que explican la competitividad según el Índice de Competitividad Turística son: Habilitación del Entorno, Políticas y Condiciones de Habilitación, Infraestructura y Recursos Naturales y Culturales. Dentro de los principales resultados se encuentra que el Índice de Competitividad no fue el esperado arrojando un indicador de 3,13 de una calificación en escala de 1 a 7, producto del bajo nivel de competitividad que presentaron los pilares Habilitación del Entorno y Políticas y Condiciones de habilitación.

\footnotetext{
${ }^{1}$ Este documento fue realizado a partir del Trabajo de Grado para optar al título de Economista de la Universidad de Cartagena. Asesora del Trabajo de Grado: Dennis Marrugo Torrente

2 Economista de la Universidad de Cartagena. Correo Electrónico: jealgota@gmail.com

${ }^{3}$ Economista de la Universidad de Cartagena. Correo Electrónico: teofilomoralesm@gmail.com
} 


\section{REFERENCIAS}

Aguilera, M., Mattos, C. B., y Puentes, P. Q. (2006). Turismo y desarrollo en el Caribe colombiano. BANCO DE LA REPÚBLICA-ECONOMÍA REGIONAL.

Araiza, Z., Velarde, E., y Zarate, A. (2010). Estrategias de competitividad de las micro, pequeñasy medianas empresas vinícolas de la ruta del vino del valle de Guadalupe, en baja california,méxico. Revista de Investigación, 1(8), 1-30.

Bernal, C., Quintero, P., y López, H. (2005). La competitividad turística de Cartagena de Indias: Análisis del destino y posicionamiento en el mercado. Estudios sobre la Competitividad de Cartagena, Serie, (4).

Bernier, E. T. (2015). Turismo y desarrollo regional. Papers de Turisme, (14-15), 95-102.

Brida, J. G., Monterubbianesi, P., y Zapata, S. (2011). Impactos del turismo sobre el crecimiento económico y el desarrollo. El caso de los principales destinos turísticos de Colombia. Revista de Turismo y patrimonio Cultural, 9(2), 291-303.

Castrillón, I. D., Canto, A. G., Cantorna, A. S., y Cerradelo, L. B. (2015). Análisis de losprincipales modelos explicativos de la competitividad de los destinos turísticos en el marco de lasostenibilidad. CULTUR-Revista de Cultura e Turismo, 5(2), 101-124.

Collazos, A. Z., y Palacio, M. C. (2012). Turismo en Colombia: resultados del sector (20072010). Magazín Empresarial, 8(15), 67-73.

Cunin, E. (2010). "Escápate a un Mundo... fuera de este Mundo": 1 turismo, globalización y alteridad. Los cruceros por el Caribe en Cartagena de Indias (Colombia). Boletín de antropología, 20(37), 131-151.

Díez Santo, D. (2012). La competitividad turística en espacios interiores: una propuestametodológica para la determinación de competidores potenciales. Cuadernos de Turismo, (30).

Galvis, L. A., y Aguilera, M. M. (1999). Determinantes de la demanda por turismo hacia Cartagena, 1987-1998. Lecturas de economía, (51), 47-87.

Garín, T. y Moral, M. J (2016). Competitividad del Sector Turístico Español. Competitividad enlos mercados internaciones.

Jafari, J. (2005). El turismo como disciplina científica. Política y sociedad, 42(1), 39-56.

Jiménez Baños, P., y Aquino Jiménez, F. K. (2012). Propuesta de un modelo de competitividad de destinos turísticos. Estudios y perspectivas en turismo, 21(4), 977995.

Meisel, A. (2011). ¿Por qué perdió la costa Caribe el siglo XX? Cartagena: Banco de la República.

Mendivelso, J. C., y Rivas, D. S. (2010). Institucionalización del turismo internacional en Cartagena de Indias durante la primera década del siglo XXI.Scripta Nova: revista electrónica de geografía y ciencias sociales, (14), 74. 
Mendoza, G. (2012). Análisis del sector turismo en Cartagena, como elemento de internacionalización de la ciudad (Doctoral dissertation, Tesis de Administración. Universidad del Rosario, Bogotá, Colombia).

Molina, C. (2011). Ecoturismo en Colombia: una respuesta a nuestra invaluable riqueza natural. TURyDES. Revista de Investigación y desarrollo local, 4(10), 1-6.

Sánchez, A. G., y García, F. J. A. (2003). EL TURISMO CULTURALY EL DE SOL Y PLAYA: ¿SUSTITUTIVOS O COMPLEMENTARIOS?. Cuadernos de Turismo, (11), 97-106.

Sancho, A., y Buhalis, D. (1998). Introducción al turismo. Madrid: Organización Mundial del Turismo

Sarasa, J. L. A. (1999). Turismo y estrategias para la recuperación de las ciudades históricas. Cuadernos de Turismo, (3), 7-30.

Such, M. J., Zapata-Aguirre, S., Risso, W. A., Brida, J. G., y Pereyra, J. S. (2009). Turismo y Crecimiento Económico: Un Análisis Empírico de Colombia. Estudios y Perspectivas en Turismo, 18(1), 21-35.

Toro, G. (2003). La política pública de turismo en Colombia. Turismo y Sociedad, 2, 9-16

Valdelamar, F. I., López, L. F. I., y Barrios Aguirre, F. I. (2005). Diagnóstico de la competitividad de Cartagena: La situación de la ciudad a principios del siglo XXI.

Vidal, C. Los inicios de la industria Turística en Cartagena 1900 - 1950. Tesis de grado para optar el título de Historiadora (1998). Universidad de Cartagena. Cartagena de Indias.

Villareal, R., y Van Der Horst, A. (2008). Estrategia de competitividad turística de la RepúblicaDominicana. ARA, Revista de Investigación en Turismo, 1(1), 15-28. 